\title{
Türkiye'de Akademisyenlerin Kitap Yazmaya Bakış Açıları: Sakarya Üniversitesi Örneği
}

\author{
İbrahim OKUR ${ }^{*}$
}

Öz

Bu çalışmada Sakarya Üniversitesi baz alınarak fen, sosyal, eğitim ve tıp bilimlerinde çalışan öğretim elemanlarının bütün akademik hayatları boyunca ürün olarak ortaya çıkardıkları kitap, makale ve patentlerin istatistiki olarak incelenmesi yapılmış ve Öğretim Elemanlarının kitap yazımına ayırdıkları mesailerin genel durumu ortaya konulmaya çalışılmıştır. Öğretim elemanlarının akademik ürünler ortaya koymadaki performanslarının üniversite içinde geliştirilmiş olan akademik ilerleme kriterlerinden çok, ülke çapında ortaya konan akademik ilerleme kriterlerine göre şekillendikleri açı̆̆a çıkmıştır.

Anahtar Kelimeler: Akademisyen, kitap ve makale yazımı, ulusal ilerleme kriterleri

\section{Academician's Outlook at Writing Scientific Papers and Books in Turkey: Sakarya University Example}

\begin{abstract}
In this work, it is aimed to look at the tendency for the faculty members at the Sakarya University to writing scientific papers and books and to understand the reasons why the faculty members prefer one to another. This search has been performed statistically and the system of SABİS of Sakarya University has been used to collect the raw data. As a result it has been found that the choices made by the faculty members are mainly being directed by the national academical progressing criteria rather than the university own posting criteria.
\end{abstract}

Keywords: Academicians, writing papers and books, national progressing criteria, Sakarya University

* Prof.Dr., Sakarya Üniversitesi, iokur@sakarya.edu.tr 


\section{GİRIŞ}

Akademik hayatın içinde bulunan Öğretim Elemanları (Öğretim Görevlisi, Okutman, Uzman, Yardımcı Doçent, Doçent ve Profesörler) uzun bir akademik eğitim hayatının ardından (Lisans, Yüksek Lisans ve Doktora) üniversitelerde ders anlatımı, makale, kitap ve proje yazımı ile birlikte birçok bürokratik işlemler yumağının içine girmektedirler. Öğretim Elemanı olduktan sonraki süreçte kendilerini akademik çalışmalarıyla yenileyip, modern ilmin gerekliliklerini yerine getirirlerken akademik ilerleme süreçlerinden de geçmekte (Doktora, Doçentlik ve Profesörlük aşamaları gibi) ve akademik hayatlarında bir takım ürünler vermektedirler. Yazılan ulusal ya da uluslararası kitaplar, ulusal ya da uluslararası dergilerde yayımlanan makaleler ve aldıkları patentler bu ürünlerin arasında sayılabilecek en önemli sonuçlardır.

Akademisyenlerin bu akademik ilerleme süreçlerinde önlerine konulan yeterlikler ve atama ölçütlerinin kendilerinin akademik araştırma ve ürün verme hayatlarını etkilediği yadsınamaz bir gerçektir. Sosyal bilimler alanlarında akademisyenlerin önüne konulan ölçütler ile sayısal, tıp bilimleri veya eğitim bilimleri alanında çalışan akademisyenlerin teşvik edildikleri kıstaslar farklılaşabilmekte ve bu da değişik bilim dallarında çalışan bilim insanlarının akademik hayatlarını son derece önemli ölçüde etkileyebilmektedir.

Türkiye'de ürün olarak açığa çıkan akademik çalışmaların geneli incelendiğinde bahsi geçen durumun süreci son derece etkin bir şekilde kontrol altında tuttuğu görülmektedir. Akademik eğitim, öğretim ve araştırma alanlarında yer alanların (Öğrenci-Öğretim Elemanları) toplamı düşünülerek ( $k i$ bu dünya çapında da ele alınabilir) ihtiyaç/arz-talep dengesi açısından bakıldığında, hangi ürünlere daha çok ihtiyacın olduğu ile sonuç ürünlerinin (özellikle kitap ve makaleler) pek de dengeli olmadığg 1 görülmektedir.

Bir uluslararası makaleyi kaç kişi okur/kaç kişinin bu makalenin ifade ettiklerine ihtiyacı vardır? Ulusal ya da uluslararası yazılmış bir kitabı kaç kişi okur/kaç kişi bu kitabın içeriğinden faydalanır? Türkiye'de bu ihtiyaç oranında mı eser verilmektedir, yoksa akademik ilerleme düşünceleri/yönlendirmeler mi akademisyenleri bu soruna çare aramaya itmektedir?

Bu çalışmada Sakarya Üniversitesi baz alınarak akademisyenlerin kitap yazma sürecindeki tutumları istatistiki bir tarzda ele alınmış; akademisyenlerin sosyal, sayısal, tıp ve eğitim bilimlerinde vermiş oldukları ürünlerin analizi, akademisyenlerin bütün akademik hayatları boyunca (ortalama 20 yıl) yapmıs oldukları yayınlar incelenerek mümkün olduğunca bölüm bazında yapılmaya çalışılmıştır.

\section{YÖNTEM}

Sakarya Üniversitesinin değişik fakülte ve yüksekokullarında çalışmakta olan Öğretim elemanlarının (Öğretim Görevlisi, Uzman, Yardımcı Doçent, Doçent ve Profesör) bütün akademik hayatlarında ürün olarak ortaya koydukları ulusal yada uluslararası ürünleri (kitap, makale, patent) Sakarya Üniversitesi Akademik Bilgi Sisteminden yararlanılarak (WEB1) ayrıntılı bir şekilde (ilk olarak şahıs bazında) incelenmiş ve ilgili elemanların temel olarak bölümleri baz alınarak vermiş oldukları ürünler/çıktılar bölümde çalışan personel sayısına bölünmek suretiyle Öğretim Elemanı başına (\%) ürün sayılarına ulaşılmıştır. $\mathrm{Bu}$ işlemde (toplam çalışma sayısı $/$ kişi sayısı $=\%$ ürün) oranlaması yapılmıştır. Aynı işlem bilim dalları (fen, sosyal, eğitim ve tıp) çerçevesinde de değerlendirilmiş ve bu veriler akademik yarar açısından değerlendirilmişlerdir. 


\section{SONUÇLAR ve DEĞERLENDİRME}

2013 Aralık ayı itibariyle Sakarya Üniversitesi 4 yıllık Fakülte ve Yüksekokullarındaki Öğretim Elemanlarının bütün akademik hayatlarında çıkarmış oldukları toplam ürün sayılarına ve bu sayıların Öğretim Elemanı sayısına oranına bakılarak üniversite geneli için Tablo 1'deki sonuçlara ulaşılmıştır.

Tablo 1. Sakarya Üniversitesi Öğretim Elemanlarının Bütün Akademik Hayatları Boyunca Yapmış Oldukları Yayın Sayıları ve Bunun Eleman Başına Oranları (Üniversite genelinde)

\begin{tabular}{llllllllll}
\hline $\begin{array}{l}\text { Öğretim } \\
\text { Elemanı }\end{array}$ & $\begin{array}{l}\text { Ulusal } \\
\text { Kitap }\end{array}$ & $\begin{array}{l}\text { Ulusal } \\
\text { Kitap } \\
(\%)\end{array}$ & $\begin{array}{l}\text { Uluslararası } \\
\text { Kitap }\end{array}$ & $\begin{array}{l}\text { Uluslararası } \\
\text { Kitap (\%) }\end{array}$ & $\begin{array}{l}\text { Ulusal } \\
\text { Makale }\end{array}$ & $\begin{array}{l}\text { Ulusal } \\
\text { Makale(\%) }\end{array}$ & $\begin{array}{l}\text { Uluslararası } \\
\text { Makale }\end{array}$ & $\begin{array}{l}\text { Uluslararası } \\
\text { Makale }(\%)\end{array}$ & $\begin{array}{l}\text { Patent } \\
\text { ve \% }\end{array}$ \\
\hline 957 & 1709 & 1,786 & 154 & 0,161 & 3172 & 3,315 & 6296 & 6,579 & $8-0.01$ \\
\hline
\end{tabular}

Bu sayı ve oranlara bakıldı̆̆ında ürünler içerisinde patent sayısı ve uluslararası kitap yazma oranının son derece düşük değerde kaldı̆̆ı görülmektedir. Örneğin uluslararası kitap yazma oranının, uluslararası yayın oranının 40 'ta biri ve ulusal kitap yayın oranının ise 12 'de biri seviyesinde olduğu, Tabloda (Tablo 1) en büyük verimle ulaşılan birimin uluslararası yayın olduğu görülmektedir. Sakarya Üniversitesinin akademik yükseltme ve atanma ölçütlerinde ise bu oranlara uygun olmayan puanlamanın yapıldığı düşünüldüğünde (uluslararası kitap 100 puan, ulusal kitap 65 puan, uluslararası yayın 100 puan) (WEB2), akademisyenlerin üniversite içindeki ilerleme kriterlerinden çok akademik ünvan sınavlarında (doçentlik sınavı, tıpta uzmanlık sınavı gibi) yer alan puantajlara göre ürün vermeye çalıştıkları sonucuna varılmaktadir.

Fen, Sosyal, Eğitim ve Tıbbi Bilimler bazında olaya bakıldığında ise, bölümler bazında bazı sapmalar görülmekle birlikte; Fen, Eğitim Tıbbi Bilimlerde uluslararası makalelerde yoğunlaşma olduğu; Sosyal Bilimlerde ise ulusal kitap yazma oranının bir miktar daha üst seviyelerde seyrettiği görülmektedir (bkz. Tablo 2-3-4-5).

Bu tablolar (Tablo 2-5) dikkatli incelendiğinde ulusal kitap yazma oranının en yüksek olduğu bölümlerin Turizm İşletmeciliği (10,000),
Hukuk $(7,667)$, Kaynarca Uygulamalı Bilimler $(7,000)$, İslam Tarihi ve Sanatları $(6,700)$ ve Uluslararası İlişkiler $(6,417)$ bölümleri olduğu görülmektedir. Uluslararası kitapta en yüksek oranların Kaynarca Uygulamalı Bilimler $(3,000)$, İnsan Kaynakları ve Yönetimi $(1,000)$, İktisat $(0,889)$, Tarih $(0,800)$ ve Maliye $(0,750)$ bölümlerinde gerçekleştiği; Ulusal makale alanında en yüksek yayın sıralamasının Yapı Eğitimi (22,000), Hukuk (21,500), Hemşirelik $(11,182)$, ve Turizm İşletmeciliği $(9,429)$ şeklinde gerçekleştiği ve uluslararası makale alaninda ise bu siralamanın Fizik $(21,730)$, Metalurji ve Malzeme Mühendisliği (20,000), Kimya (15,469), Finansal Ekonometri $(12,600)$ ve Matematik $(11,640)$ olarak karşımıza çıktığı görülmektedir. Bu sıralamada da akademisyenlerin akademik yükselme ölçütlerine göre çalışmalarına yön verdikleri açıça görülmektedir. 
Tablo 2. Fen Bilimleri Akademik Çalışma ve Oranlarının Bölümlere Göre Dağılımı

\begin{tabular}{|c|c|c|c|c|c|c|c|c|c|}
\hline Bölüm & $\begin{array}{l}\text { Öğretim } \\
\text { Elemanı }\end{array}$ & $\begin{array}{l}\text { Ulusal } \\
\text { Kitap }\end{array}$ & $\begin{array}{l}\text { Ulusal } \\
\text { Kitap } \\
(\%)\end{array}$ & $\begin{array}{l}\text { Uluslararası } \\
\text { Kitap }\end{array}$ & $\begin{array}{l}\text { Uluslararası } \\
\text { Kitap (\%) }\end{array}$ & $\begin{array}{l}\text { Ulusal } \\
\text { Makale }\end{array}$ & $\begin{array}{l}\text { Ulusal } \\
\text { Makale } \\
(\%)\end{array}$ & $\begin{array}{l}\text { Uluslararası } \\
\text { Makale }\end{array}$ & $\begin{array}{l}\text { Uluslararası } \\
\text { Makale (\%) }\end{array}$ \\
\hline Fizik & 26 & 17 & 0,654 & 0 & 0,000 & 24 & 0,923 & 565 & 21,730 \\
\hline $\begin{array}{l}\text { Met.- } \\
\text { Malzeme }\end{array}$ & 31 & 6 & 0,194 & 1 & 0,032 & 89 & 2,871 & 620 & 20,000 \\
\hline $\begin{array}{l}\text { Metalurji - } \\
\text { Malzeme } \\
\text { (TEF) }\end{array}$ & 11 & 11 & 1,000 & 0 & 0,000 & 74 & 6,727 & 220 & 20,000 \\
\hline Kimya & 32 & 1 & 0,031 & 2 & 0,062 & 54 & 1,688 & 495 & 15,649 \\
\hline Matematik & 25 & 18 & 0,720 & 0 & 0,000 & 50 & 2,000 & 291 & 11,640 \\
\hline Gida & 8 & 6 & 0,750 & 2 & 0,250 & 56 & 7,000 & 85 & 10,625 \\
\hline İnşaat(TEF) & 9 & 3 & 0,333 & 3 & 0,333 & 59 & 6,556 & 92 & 10,222 \\
\hline Biyoloji & 10 & 5 & 0,200 & 0 & 0,000 & 25 & 2,500 & 101 & 10,100 \\
\hline Makina & 42 & 13 & 0,310 & 1 & 0,024 & 68 & 1,619 & 342 & 8,143 \\
\hline $\begin{array}{l}\text { Elektrik- } \\
\text { Elektronik } \\
\text { (TEF) }\end{array}$ & 9 & 8 & 0,889 & 0 & 0,000 & 18 & 2,000 & 73 & 8,111 \\
\hline Makine(TEF) & 7 & 1 & 0,143 & 0 & 0,000 & 13 & 1,857 & 55 & 7,857 \\
\hline Çevre & 21 & 3 & 0,143 & 2 & 0,095 & 50 & 2,381 & 149 & 7,095 \\
\hline $\begin{array}{l}\text { Bilgisayar } \\
\text { (TEF) }\end{array}$ & 6 & 6 & 1,000 & 2 & 0,333 & 13 & 2,167 & 41 & 6,833 \\
\hline Bilgisayar & 15 & 17 & 1,133 & 2 & 0,133 & 52 & 3,467 & 91 & 6,067 \\
\hline $\begin{array}{l}\text { Mekatronik } \\
\text { (TEF) }\end{array}$ & 8 & 9 & 1,125 & 0 & 0,000 & 13 & 1,625 & 48 & 6,000 \\
\hline $\begin{array}{l}\text { Elektrik- } \\
\text { Elektronik }\end{array}$ & 27 & 20 & 0,741 & 0 & 0,000 & 64 & 2,370 & 154 & 5,704 \\
\hline İnşaat & 30 & 14 & 0,467 & 5 & 0,167 & 66 & 2,200 & 149 & 4,967 \\
\hline Endüstri & 30 & 19 & 0,633 & 2 & 0,067 & 47 & 1,567 & 138 & 4,600 \\
\hline Jeofizik & 10 & 6 & 0,600 & 1 & 0,100 & 29 & 2,900 & 34 & 3,400 \\
\hline İstatistik & 1 & 0 & 0,000 & 0 & 0,000 & 2 & 2,000 & 3 & 3,000 \\
\hline Bilişim & 6 & 14 & 2,333 & 0 & 0,000 & 19 & 3,167 & 13 & 2,167 \\
\hline Toplam & 364 & 197 & 0,541 & 23 & 0,063 & 885 & 2,431 & 3768 & 10,352 \\
\hline
\end{tabular}

${ }^{*}$ TEF: Teknoloji Fakültesi

Tablo 3. Sosyal Bilimler Akademik Çalışma ve Oranlarının Bölümlere Göre Dağılımı

\begin{tabular}{|c|c|c|c|c|c|c|c|c|c|}
\hline Bölüm & $\begin{array}{l}\text { Öğretim } \\
\text { Elemanı }\end{array}$ & $\begin{array}{l}\text { Ulusal } \\
\text { Kitap }\end{array}$ & $\begin{array}{l}\text { Ulusal } \\
\text { Kitap(\%) }\end{array}$ & $\begin{array}{l}\text { Uluslararası } \\
\text { Kitap }\end{array}$ & $\begin{array}{l}\text { Uluslararası } \\
\text { Kitap (\%) }\end{array}$ & $\begin{array}{l}\text { Ulusal } \\
\text { Makale }\end{array}$ & $\begin{array}{l}\text { Ulusal } \\
\text { Makale } \\
(\%)\end{array}$ & $\begin{array}{l}\text { Uluslararası } \\
\text { Makale }\end{array}$ & $\begin{array}{l}\text { Uluslararası } \\
\text { Makale (\%) }\end{array}$ \\
\hline $\begin{array}{l}\text { Finansal } \\
\text { Ekonome- } \\
\text { tri }\end{array}$ & 5 & 4 & 0,800 & 1 & 0,200 & 10 & 2,000 & 63 & 12,600 \\
\hline $\begin{array}{l}\text { Sağllk } \\
\text { Yönetimi }\end{array}$ & 5 & 27 & 5,400 & 0 & 0,000 & 34 & 6,800 & 58 & 11,600 \\
\hline İktisat & 18 & 81 & 4,500 & 16 & 0,889 & 145 & 8,056 & 137 & 7,611 \\
\hline $\begin{array}{l}\text { Yönetim } \\
\text { İletişim }\end{array}$ & 7 & 13 & 1,857 & 4 & 0,571 & 13 & 1,857 & 44 & 6,286 \\
\hline $\begin{array}{l}\text { İnsan Kay. } \\
\text { Yönetimi }\end{array}$ & 5 & 16 & 3,200 & 5 & 1,000 & 21 & 4,200 & 29 & 5,800 \\
\hline $\begin{array}{l}\text { Sosyal } \\
\text { Hiz. }\end{array}$ & 6 & 25 & 4,167 & 0 & 0,000 & 48 & 8,000 & 28 & 4,667 \\
\hline $\begin{array}{l}\text { Turizm } \\
\text { İşlet. }\end{array}$ & 7 & 70 & 10,000 & 3 & 0,429 & 66 & 9,429 & 29 & 4,143 \\
\hline Maliye & 8 & 47 & 5,875 & 6 & 0,750 & 67 & 8,375 & 33 & 4,125 \\
\hline $\begin{array}{l}\text { Uluslarara } \\
\text { S1 Ticaret }\end{array}$ & 8 & 9 & 1,125 & 2 & 0,250 & 23 & 2,875 & 32 & 4,000 \\
\hline İşletme & 27 & 146 & 5,407 & 9 & 0,333 & 173 & 6,407 & 100 & 3,704 \\
\hline Coğrafya & 9 & 17 & 1,889 & 6 & 0,667 & 42 & 4,667 & 32 & 3,556 \\
\hline $\begin{array}{l}\text { Uluslar } \\
\text { arası } \\
\text { İlişkiler }\end{array}$ & 12 & 77 & 6,417 & 2 & 0,167 & 19 & 1,584 & 38 & 3,167 \\
\hline Tarih & 25 & 140 & 5,600 & 20 & 0,800 & 104 & 4,160 & 62 & 2,480 \\
\hline $\begin{array}{l}\text { Siyaset } \\
\text { Bil.- Kamu } \\
\text { Yön. }\end{array}$ & 16 & 28 & 1,750 & 2 & 0,125 & 41 & 2,563 & 32 & 2,000 \\
\hline $\begin{array}{l}\text { T.Dili ve } \\
\text { Ed. }\end{array}$ & 19 & 66 & 3,474 & 1 & 0,053 & 30 & 1,579 & 37 & 1,947 \\
\hline $\begin{array}{l}\text { İletişim } \\
\text { Bilimleri }\end{array}$ & 5 & 1 & 0,200 & 0 & 0,000 & 7 & 1,400 & 9 & 1,800 \\
\hline İslam & 40 & 268 & 6,700 & 28 & 0,700 & 226 & 5,650 & 57 & 1,425 \\
\hline
\end{tabular}




\begin{tabular}{|c|c|c|c|c|c|c|c|c|c|}
\hline \multicolumn{10}{|l|}{$\begin{array}{l}\text { Tarihi ve } \\
\text { Sanatlar1 }\end{array}$} \\
\hline $\begin{array}{l}\text { Halkla } \\
\text { Ilişsk. }\end{array}$ & 3 & 17 & 5,667 & 0 & 0,000 & 11 & 3,667 & 4 & 1,333 \\
\hline $\begin{array}{l}\text { Reklam. } \\
\text { Sosyoloji }\end{array}$ & 13 & 30 & 2,308 & 0 & 0,000 & 25 & 1,923 & 17 & 1,308 \\
\hline $\begin{array}{l}\text { Çalışma } \\
\text { Eko- End. } \\
\text { İlişkiler }\end{array}$ & 14 & 24 & 1,714 & 0 & 0,000 & 29 & 2,071 & 17 & 1,214 \\
\hline $\begin{array}{l}\text { Temel } \\
\text { İslam } \\
\text { Bilimleri }\end{array}$ & 10 & 44 & 4,400 & 3 & 0,300 & 88 & 8,800 & 12 & 1,200 \\
\hline Sanat Tar. & 5 & 18 & 3,600 & 2 & 0,400 & 18 & 3,600 & 5 & 1,000 \\
\hline $\begin{array}{l}\text { Görsel } \\
\text { İletişim } \\
\text { Tas. }\end{array}$ & 7 & 5 & 0,714 & 2 & 0,286 & 20 & 2,857 & 6 & 0,857 \\
\hline $\begin{array}{l}\text { Çeviri- } \\
\text { bilim }\end{array}$ & 10 & 17 & 1,700 & 0 & 0,000 & 8 & 0,800 & 8 & 0,800 \\
\hline $\begin{array}{l}\text { Alman } \\
\text { Dili }\end{array}$ & 9 & 8 & 0,889 & 1 & 0,111 & 24 & 2,667 & 7 & 0,778 \\
\hline Hukuk & 6 & 46 & 7,667 & 0 & 0,000 & 129 & 21,500 & 4 & 0,667 \\
\hline Felsefe & 7 & 25 & 3,571 & 0 & 0,000 & 15 & 2,143 & 4 & 0,571 \\
\hline $\begin{array}{l}\text { Seramik } \\
\text { ve Cam }\end{array}$ & 8 & 3 & 0,375 & 0 & 0,000 & 2 & 0,250 & 1 & 0,125 \\
\hline Resim & 9 & 1 & 0,111 & 0 & 0,000 & 11 & 1,222 & 1 & 0,111 \\
\hline $\begin{array}{l}\text { Gele- } \\
\text { neksel } \\
\text { Türk El } \\
\text { San. }\end{array}$ & 10 & 2 & 0,200 & 0 & 0,000 & 4 & 0,400 & 1 & 0,100 \\
\hline Grafik & 2 & 0 & 0,000 & 0 & 0,000 & 0 & 0,000 & 0 & 0,000 \\
\hline $\begin{array}{l}\text { Din } \\
\text { Kültürü- } \\
\text { Ahlak } \\
\text { Bilgisi }\end{array}$ & 2 & 0 & 0,000 & 0 & 0,000 & 0 & 0,000 & 0 & 0,000 \\
\hline Toplam & 337 & 1275 & 3,783 & 113 & 0,335 & 1463 & 4,341 & 907 & 2,691 \\
\hline
\end{tabular}

Tablo 4. Eğitim Bilimleri Akademik Çalışma ve Oranlarının Bölümlere Göre Dağılımı

\begin{tabular}{|c|c|c|c|c|c|c|c|c|c|}
\hline Bölüm & $\begin{array}{l}\text { Öğretim } \\
\text { Elemanı }\end{array}$ & $\begin{array}{l}\text { Ulusal } \\
\text { Kitap }\end{array}$ & $\begin{array}{l}\text { Ulusal } \\
\text { Kitap } \\
(\%)\end{array}$ & $\begin{array}{l}\text { Uluslararası } \\
\text { Kitap }\end{array}$ & $\begin{array}{l}\text { Uluslararası } \\
\text { Kitap (\%) }\end{array}$ & $\begin{array}{l}\text { Ulusal } \\
\text { Makale }\end{array}$ & $\begin{array}{l}\text { Ulusal } \\
\text { Makale } \\
(\%)\end{array}$ & $\begin{array}{l}\text { Uluslararası } \\
\text { Makale }\end{array}$ & $\begin{array}{l}\text { Uluslararas1 } \\
\text { Makale (\%) }\end{array}$ \\
\hline Metal E. & 4 & 0 & 0,000 & 0 & 0,000 & 24 & 6,000 & 40 & 10,000 \\
\hline Makine E. & 10 & 0 & 0,000 & 0 & 0,000 & 18 & 1,800 & 94 & 9,400 \\
\hline Eğitim Bil. & 20 & 60 & 3,000 & 4 & 0,200 & 130 & 6,500 & 163 & 8,150 \\
\hline $\begin{array}{l}\text { Ortaöğretim } \\
\text { Sos.Al. Eğt. }\end{array}$ & 3 & 17 & 5,667 & 0 & 0,000 & 14 & 4,667 & 21 & 7,000 \\
\hline Yap1 E. & 1 & 3 & 3,000 & 0 & 0,000 & 22 & 22,000 & 7 & 7,000 \\
\hline $\begin{array}{l}\text { Ortaöğretim } \\
\text { Fen ve } \\
\text { Mat.Al.Eğt. }\end{array}$ & 2 & 0 & 0,000 & 0 & 0,000 & 0 & 0,000 & 13 & 6,500 \\
\hline İlköğretim & 35 & 30 & 0,857 & 4 & 0,114 & 78 & 2,229 & 193 & 5,514 \\
\hline ВÖTE & 9 & 8 & 0,889 & 3 & 0,333 & 24 & 2,667 & 41 & 4,556 \\
\hline Elk-Bilg Ĕ̆t. & 4 & 2 & 0,500 & 0 & 0,000 & 3 & 0,750 & 17 & 4,250 \\
\hline $\begin{array}{l}\text { Türkçe } \\
\text { Eğitimi }\end{array}$ & 9 & 47 & 5,222 & 3 & 0,333 & 52 & 5,778 & 37 & 4,111 \\
\hline Y.Diller & 3 & 0 & 0,000 & 0 & 0,000 & 4 & 1,333 & 10 & 3,333 \\
\hline Özel Eğitim & 3 & 2 & 0,667 & 0 & 0,000 & 6 & 2,000 & 7 & 2,333 \\
\hline Toplam & 103 & 169 & 1,641 & 14 & 0,136 & 365 & 3,544 & 643 & 6,243 \\
\hline
\end{tabular}

Tablo 5. Tıbbi Bilimler Akademik Çalışma ve Oranlarının Bölümlere Göre Dağglımı

\begin{tabular}{llllllllll}
\hline Bölüm & $\begin{array}{l}\text { Ögratim } \\
\text { Elemanı }\end{array}$ & $\begin{array}{l}\text { Ulusal } \\
\text { Kitap }\end{array}$ & $\begin{array}{l}\text { Ulusal } \\
\text { Kitap } \\
(\%)\end{array}$ & $\begin{array}{l}\text { Uluslararası } \\
\text { Kitap }\end{array}$ & $\begin{array}{l}\text { Uluslararası } \\
\text { Kitap (\%) }\end{array}$ & $\begin{array}{l}\text { Ulusal } \\
\text { Makale }\end{array}$ & $\begin{array}{l}\text { Ulusal } \\
\text { Makale } \\
(\%)\end{array}$ & $\begin{array}{l}\text { Uluslararası } \\
\text { Makale }\end{array}$ & $\begin{array}{l}\text { Uluslararası } \\
\text { Makale (\%) }\end{array}$ \\
\hline $\begin{array}{l}\text { Temel Tıp } \\
\text { Bilimleri }\end{array}$ & 16 & 1 & 0,063 & 0 & 0,000 & 76 & 4,750 & 155 & 9,688 \\
$\begin{array}{l}\text { Dahili Tıp } \\
\text { Bilimleri } \\
\text { Cerrahi Tıp }\end{array}$ & 37 & 8 & 0,216 & 0 & 0,000 & 62 & 1,676 & 332 & 8,973 \\
$\begin{array}{l}\text { Bilimleri } \\
\text { Toplam }\end{array}$ & 41 & 20 & 0,488 & 0 & 0,000 & 123 & 3,000 & 260 & 6,341 \\
\hline
\end{tabular}


Şahıs bazında yapılan incelemede en yüksek sayıda yapilan yayınlar siralamaya konulduğunda; ulusal kitap sayısı açısından H.T (69 kitap, İşletme Bölümü), K.İ (49 kitap, Uluslararası İlişkiler Bölümü), F.A (39 kitap, İslam Tarihi Bölümü); uluslararası kitap sayısı açısından M.İ (18 kitap, İslam Tarihi Bölümü), A.V. C (8 kitap, İşletme Bölümü), A.B (7 kitap, Tarih Bölümü); ulusal makale sayısı açısından E.A (86 makale, Hukuk Bölümü), D.A (60 makale, Temel İslam Bilimleri Bölümü), M.Ç (58 makale, Hemşirelik); uluslararası makale sayısı açısından R.A (135 makale, Kardiyoloji Bölümü), Ü.E (107 makale, Biyoistatistik Bölümü), H.M.T (82 makale, Fizik) şeklinde bir sonucun açığa çıktığı gözlenmiştir. Bu sonuçlar da sayısal branşlarda daha çok uluslararası makaleye yönelim varken sosyal branşlarda ulusal yayınlara ilginin daha çok olduğunu göstermektedir.

Ulusal ya da uluslararası kitap yazımı konusunda üniversitenin son derece düşük seviyede kaldığını gösteren bu sonuçlardan en ilginç olanlarından birisi, en çok uluslararası makale yapan bölümlerin (Fizik, Metalurji ve Kimya Bölümleri) ulusal ve uluslararası kitap yazımında son derece düşük oranlarda kalmaları (üç bölümün ulusal kitap ortalaması: 0.55, uluslararası kitap ortalaması 0.02 ) ve en çok uluslararası makale yazan ilk iki akademisyenin ulusal ya da uluslararası kitabının bulunmamasıdır.

Yapılan genel incelemede kitap yazmamış Öğretim Elemanı sayısının 582 kişiyle $\% 60.8^{\prime}$ lik bir orana ulaştığı ve hiç ulusal ya da uluslararası makale yazmamış Öğretim Ele- manı sayısının ise 246 kişi (\%25.7) olduğu sonucuna ulaşılmıştır. Bu sonuçlar genel manada Sakarya Üniversitesi Öğretim Elemanlarının, gerek Türkiye genelinde yapılan akademik yükselme sinavları ve gerekse Üniversite içinde uygulanan akademik yükseltme ölçütleri çerçevesine daha çok uluslararası makaleye yöneldiklerini göstermektedir.

Akademik hayatın vazgeçilmezleri arasında yer alan akademik faaliyet çıtılarının (kitap, makale, patent) gerek ülkemiz, gerekse uluslararası arenada sağlayacağı faydalar göz önüne alındığında Öğretim Üyelerinin ürettikleri uluslararası makalelerin yeri elbette ayrıdır. Ancak ulusal ya da uluslararası kitapların hitap ettikleri kitle göz önüne alındığında, bu kitapları yazmak için hasredilen akademik mesai saatlerinin özellikle Fen ve Tıp bilimlerinde hiç de arzu edilen seviyede olmadıkları görülmektedir. $\mathrm{Bu}$ çerçevede yapılacak destekler ve düzenlemelerle bu durumun pozitif yöne doğru gitmesi sağlanmalıdır. Kitap yazma işinin sadece üniversiteler dışındaki yazarlara bırakılması veya böyle bir görüntünün çizilmesi başta Sakarya Üniversitesi olmak üzere bütün Üniversitelerimiz için oldukça negatif bir bilimsel iz birakacaktır.

\section{TEŞEKKÜR}

Sakarya Üniversitesi Rektörlüğüne akademik bilgi sisteminin hazırlanması ve bunun herkese ulaşılabilir olmasını sağlamadaki büyük gayretlerinden ötürü teşekkürü bir borç bilirim.

\section{Kaynakça}

WEB1, http://www.sabis.sakarya.edu.tr

WEB2, http://www.personel.sakarya.edu.tr 


\section{Extended Summary}

In this work, it is aimed to look at the tendency for the faculty members at the Sakarya University to writing scientific papers and books and to understand the reasons why the faculty members prefer one to another. This search has been performed statistically and the system of SABIS of Sakarya University has been used to collect the raw data.

First of all, personal data from the SABIS have been collected and classified person to person. These data have then been organised as amount of national/international boks and number of national/international manuscripts and then these data have been tabulated according to the departments. In this context the science, art, education and medical disciplines are classified individually to see the interdisciplinary differences. All numbers/amounts of scientific outcomes are then statictically evaluated by dividing the numbers by the total academic staff of the academic unit.

From the results it has been found that the patent and international book amounts and percentages seem to be very low. For example the internationa book percentage is one forth of the international paper percentange and one twelfth of the national book ratio. The highest ratio is reached in international papers. This difference is attributed to the fact that the academic progressing crieteria is taken into account by the faculty members.

In the science, medical and educational departments, papers are dominantly chosen by the academician whereas in social sciences national book ratio seems to be effectively chosen by the university staff. Another interesting result is that the departments of Physics, Metallurgy and Chemistry that have highest international paper ratio stay in a very low national and international book ratios.

As a result it has been found that the choices made by the faculty members are mainly being directed by the national academical progressing criteria rather than the university own posting criteria. It has been concluded that the faculty members in Turkey (as a special case in Sakarya University) are not very keen on writing academic and social books when compared to the authors who are not academician due to the fact that the support in writing books is not in the desired level. 